\title{
Qualitative study of Nocebo Phenomenon (NP) involved in doctor-patient communication
}

\author{
Bushra Ashraf ${ }^{1}$, Muhammad Saaiq $^{2, *}$, Khaleeq-Uz-Zaman ${ }^{3}$
}

\begin{abstract}
Background: Doctor-patient communication has far reaching influences on the overall well-being of the patients. Words are powerful tools in the doctor's armamentarium, having both healing as well as harming effects. Doctors need to be conscious about the choice of their words. This study aimed to determine the frequency and pattern of Nocebo Phenomenon (NP) un-intentionally induced by the communication of surgeons and anesthetists through the course of various interventional procedures such as surgery, anesthesia, and crucial communication encounters with their patients.

Methods: The study was carried out by the Department of Medical Education (DME), Pakistan Institute of Medical Sciences (PIMS), Shaheed Zulfiqar Ali Bhutto Medical University (SZABMU), Islamabad over six months period. All residents and faculty members serving at our institute in various surgical and anesthesia departments constituted the study population. A questionnaire was employed as the data collection tool. Results: Significant proportions of the doctor-patient communications under scrutiny entailed NP. It was more frequently observed in association with female gender of the involved professionals, residency status versus faculty position, and shorter professional experience (i.e. $<5$ years). Although the participants endorsed the fact that the choice of their words influenced the well-being of their patients, none of them were actually aware of the concept of NP.

Conclusion: NP existed in the clinical practice of the surgeons and anesthetists during their communication with patients. It was more frequently found among females, residents and professionals with less than five years of working experience. There is need to create awareness among these professionals about the subtle negative messages conveyed by such communication and alert them that the nocebo effects have negative repercussions on the clinical outcomes of their patients. The professionals should be formally educated to avoid nocebo words and phrases.

Keywords: Nocebo Phenomenon (NP), Nocebo Words, Nocebo Effects, Nocebo Response, Placebo Phenomenon, Doctor-Patient Communication

Copyright: @ 2014 by Kerman University of Medical Sciences

Citation: Ashraf B, Saaiq M, Zaman KU. Qualitative study of Nocebo Phenomenon (NP) involved in doctorpatient communication. Int J Health Policy Manag 2014; 3: 23-27. doi: 10.15171/ijhpm.2014.54
\end{abstract}

Article History:

Received: 1 April 2014 Accepted: 31 May 2014 ePublished: 2 June 2014

\section{Introduction}

The Nocebo Phenomenon (NP) entails unintended communication of verbal or non-verbal suggestions of negative outcomes with the result that the patient expects and experiences either worsening of pre-existing clinical symptoms or the emergence of some new ones. The triggering of these responses ensue via psychological and neurobiological mechanisms including subconscious conditioning as well as conscious expectations (1-3). The term nocebo was originally coined by Kennedy WP who employed it to denote the negative equivalent of placebo phenomenon and differentiate desirable from undesirable effects of placebos in the context of sham treatments (3). NP encompass nocebo effect as well as nocebo response. The former refers to the new or worsening symptoms that may occur during sham treatments or as a result of deliberate or unintended suggestion and/or negative expectations. The nocebo response is employed to mean new and worsening symptoms in the absence of any sham treatment $(1,4)$.

The various possible mechanisms that underlie NP include Pavlovian conditioning, expectations and previous social experiences. In fact both placebo and nocebo responses can be acquired through all kinds of learning and when these happen in the context of everyday clinical practice, these may emanate from either the patient's expectations or their previous similar experiences (4-8). Neurobiologically, dopamine and endogenous opiates have been shown to serve as the central mediators of these phenomena. Several studies have objectively assessed the cortical processes involved in these phenomena, employing brain imaging and have demonstrated the fact that the expectation of pain is associated with activation of various cortical centres such as the thalamus, insula, prefrontal cortex, and anterior cingulate cortex (9-12).

The surgeons and anesthetists should particularly be well aware of the implications of this important but neglected aspect of their communication with patients in their daily clinical practice. The present qualitative study was undertaken to determine the frequency and pattern of NP in doctor-patient communication at our hospital, find out any association of NP with the socio-demographic characteristics of the involved professionals and hence evolve actionable 
evidence base that could better guide improved quality of communication practices.

\section{Methods}

This qualitative investigation was carried out under the auspices of the Department of Medical Education (DME) at Pakistan Institute of Medical Sciences (PIMS), Shaheed Zulfiqar Ali Bhutto Medical University (SZABMU), Islamabad over a period of six months (August 01, 2013 to January 31, 2014).

PIMS is the tertiary care teaching dispensation of SZABMU and is one of the country's leading medical institutions, attracting doctors from all parts of the country to pursue various postgraduate residency programmes such as FCPS, MS, MD, MCPS and M.Phil in different clinical specialties.

\section{Study participants}

Our study population was constituted by all the residents and faculty members working in various surgical and anesthesia departments of the hospital. The target was to cover at least 120 such participants to get a representative sample. They were randomly approached face-to-face, with the help of a team of junior doctors detailed for questionnaire distribution among them.

\section{Operational definition of "nocebo phenomenon"}

For the purpose of the present study, NP was objectively defined as the unintended delivery of verbal suggestions (by doctors) of negative outcomes that had the potential to induce a negative expectation (such as pain, nausea, vomiting, bleeding) or worsening of an existing symptom among the recipients of the suggestions (i.e. patients) (1-4,13-15).

\section{Study questionnaire}

As the published literature on the NP has largely focused its discussion on the patients' perspectives and has measured the nocebo effects (particularly with regard to pain) among patients, we could not find any study where the NP had been objectively judged in the doctors' perspectives. Owing to the lack of any published study in this regard, we had to construct our own questionnaire to meet the objectives of the present study. This remained the most challenging part of the study. A good deal of effort and consideration went into designing and phrasing the questionnaire we employed. The aim was to cover all important aspects of the NP that could occur at the time of encounter of surgeons and anesthetists with their patients, during various interventional procedural sessions through the course of the patients' illness. For instance at the time of surgery, induction of anesthesia, recovery from anesthesia, change of dressings, and crucial communication sessions such as patient's counseling or consent-taking. All these situations entail stressful experiences for the patients wherein the patients' vulnerability to suggestions is heightened on one hand, and the involved professionals tend to display sympathy with them on the other hand. Hence even unintentional flaws in communication become more important and have definite negative repercussions.

We employed a series of questions to cover all possible aspects of the NP. The questionnaire was pretested on a mixed group of 20 surgeons and anesthetists and subsequently the questions were rephrased and refined to better meet the study objectives. The questionnaire entailed eight questions as summarized in Table 1.

\section{Statistical Analysis}

The data were analysed through SPSS 17 (SPSS Inc., Chicago, IL, USA). The nominal variables were reported as frequency and percentages. The numerical data were reported as Mean \pm S.D. The responses to the questions were judged as to whether bearing nocebo effects or not and the relevant percentages and statistics were calculated. The association of nocebo responses/statements with the socio-demographic profile of the participants was calculated by adding up all the nocebo responses with respect to various individual parameters such as the gender, age, education, specialty, and length of professional experience of the participants. The results were presented (Table 2) in terms of frequency and percentages. Statistical analyses for comparison of proportion were performed by employing Chi-Square test. A $P<0.05$ was considered significant.

\section{Results}

Response rate

In the target population of the doctors contacted, all the participants returned the questionnaires duly answered, constituting a response rate of $100 \%$.

\section{Demographic features of the participants included}

Out of 153 participants, 91 (59\%) were males while 62 (41\%) were females. The age range was $23-55$ years with a mean of $33.31 \pm 9.65$ years. Majority of the participants $(n=$ $101 ; 66 \%)$ were residents while the remainder $(n=52 ; 34 \%)$ were faculty members. There were 83 (54\%) participants from the surgical disciplines while $70(46 \%)$ were from the anesthesia department.

Responses to questions regarding the NP The participants variably responded to questions regarding various attributes of the NP (Table 1). The NP was more frequently observed in association with female gender of the involved professionals, residency status versus faculty position, and shorter professional experience ( $<5$ years). The association of nocebo communication with various socio-demographic characteristics of the participants is shown in Table 2.

Some of the common nocebo sentences frequently employed by the doctors are summarized in Table 3.

\section{Discussion}

While globally there has been growing awareness about the significant therapeutic as well as health threatening ramifications of the pattern and content of the various doctor-patient communications (15-19), there has been scarcity of published research on such crucial issues from developing countries like ours (Pakistan). There is also an apparent lack of realization of their importance on part of our doctors (20-22). To the best of our knowledge, our study represents the first one from Pakistan as well as the developing world to address this important but neglected aspect of communication with patients.

In our study we found high frequency of NP in the communication of surgeons and anesthetists with their 
Table 1. Responses of the participants to the questionnaire $(n=153)$

\begin{tabular}{|c|c|c|c|}
\hline & \multirow{2}{*}{ Questions } & \multicolumn{2}{|c|}{ Responses of the participants } \\
\hline & & NP & Neutral communication \\
\hline 1 & $\begin{array}{l}\text { Whenever I come across an anxious patient in the operating room or on the operating room } \\
\text { table or in the procedure room, I try to reduce the anxiety of the patient by saying }\end{array}$ & $111(72.52 \%)$ & $42(27.45 \%)$ \\
\hline 2 & $\begin{array}{l}\text { When a patient is undergoing an intervention under local anesthesia, I address the anxiety by } \\
\text { usually saying }\end{array}$ & 107 (69.93\%) & $46(30.06 \%)$ \\
\hline 3 & $\begin{array}{l}\text { In the recovery room of the operating theatre, when the patient is recovering from } \\
\text { anesthesia, I allay the anxiety, pain, nausea, vomiting of the patient by saying }\end{array}$ & $93(60.78 \%)$ & $60(39.21 \%)$ \\
\hline 4 & $\begin{array}{l}\text { At the time of changing wound dressing of my patient, I often console my patient and allay his } \\
\text { anxiety of pain by saying }\end{array}$ & $103(67.32 \%)$ & $50(32.67 \%)$ \\
\hline 5 & $\begin{array}{l}\text { Sometimes my patient needs distraction of attention and I often say the following sentences/ } \\
\text { words to do that }\end{array}$ & 119 (77.78\%) & $34(22.22 \%)$ \\
\hline 6 & $\begin{array}{l}\text { In the process of briefing to patients while taking consent or doing counseling, I explain the } \\
\text { risks of procedure by using the following effective sentences }\end{array}$ & 95 (62.09\%) & $58(37.90 \%)$ \\
\hline 7 & Can the choice of my words affect the well-being of my patients during communication & Yes $100(100 \%)$ & No - \\
\hline 8 & Do you know NP in clinical practice? & Yes - & No $100(100 \%)$ \\
\hline
\end{tabular}

patients. The daily clinical practice of these professionals involves dealing with patients who are faced with the stressful experiences or life threatening events such as accidents, injuries, acute illnesses, and the agony of undergoing surgical interventions and hence very much vulnerable to nocebo effects. In fact such patients are often in a natural trance state and thus highly suggestible to whatever their doctors communicate to them through the course of their critical care. They are also vulnerable to misunderstandings resulting from literal interpretations, ambiguities, and unclear communications $(13,23)$. One can imagine that in such situations, inappropriate words can easily negatively impact the well-being of the patient and his attending relatives who are already in a state of crisis.

In our study, the NP was more frequently observed in association with female gender of the involved professionals,

Table 2. Association of nocebo communication with various sociodemographic features of the involved professionals $(n=153)$

\begin{tabular}{lll}
\hline $\begin{array}{l}\text { Socio-demographic } \\
\text { characteristics }\end{array}$ & Number of NP (\%) & $P$ \\
\hline Gender & $49(53.84 \%)$ & $0.00^{*}$ \\
Male $(n=91)$ & $56(90.32 \%)$ & \\
Female $(n=62)$ & & $>0.05^{* *}$ \\
Age & $64(71.11 \%)$ & \\
Up to 40 years $(n=90)$ & $41(65.07 \%)$ & $0.00^{*}$ \\
$>40$ years $(n=63)$ & & \\
Education/working position & $84(83.16 \%)$ & \\
Residents $(n=101)$ & $21(40.38 \%)$ & $0.00^{*}$ \\
Faculty $(n=52)$ & & \\
Specialty & $58(69.87 \%)$ & \\
Surgery $(n=83)$ & $47(67.14 \%)$ & \\
Anesthesia $(n=70)$ & & \\
Length of professional experience & $79(94.04 \%)$ & \\
$<5$ years $(n=84)$ & $26(37.68 \%)$ & \\
$>5$ years $(n=69)$ & & \\
\hline
\end{tabular}

*Significant $P \leq 0.05 ;{ }^{* *}$ Insignificant $P \geq 0.05$ residency status versus faculty position, and shorter professional experience (i.e. $<5$ years). These individuals represent the high-risk groups who can easily err on the side of nocebo words in their communication with patients. We could not find any published study in this regard for comparison of our results.

In our study the doctors employed various words and phrases which they thought were meant to show sympathy or concern for their patients, however most of them were rather counterproductive and had the potential to intensify the feelings or symptoms which they desired to reduce or abolish otherwise. In fact the verbal and non-verbal communications of the doctors and other staff do contain numerous unintentional negative suggestions that may trigger a nocebo response (14). Many doctors employ the nocebo words in an attempt to address the patients' concern and express sympathy with them, however they simply reinforce the very symptoms (such as pain, fear, apprehension, and nausea) which they want to abolish or reduce otherwise. Lang et al. (24) observed that the patients receiving injections of radiographic medications showed heightened levels of anxiety and pain with the use of negative words such as sting, burn, hurt, bad, and pain, when explaining the procedure or expressing sympathy. Varelmann et al. (25) in their study compared the difference in perceived pain among women undergoing local anesthetic preparatory injections before induction of epidural anesthesia, with two different explanations of the procedure. i.e. "We are going to give you a local anesthetic that will numb the area so that you will be comfortable during the procedure" or "You are going to feel a big bee sting; this is the worst part of the procedure". The perceived pain was significantly greater after the latter statement.

In our study majority of the nocebo words identified belonged to the category of ineffective or counterproductive negations. For instance, "Do not worry, everything will be fine". A variety of other nocebo words were also found $(13,14)$.

Our study attempted to assess the frequency and pattern of nocebo communication with respect to the characteristics of the doctors involved in the surgical procedures, however most of the published literature on NP is either focused on patients outcomes or philosophical discussion of the issues involved 
Table 3. Some of the frequent nocebo words and sentences identified in the study $(n=153)$.

\begin{tabular}{lc}
\hline Nocebo words and sentences & Categorization (13-17) \\
\hline Do not worry, everything will be fine. & $\begin{array}{c}\text { Counterproductive } \\
\text { negation }\end{array}$ \\
Do not be afraid & - \\
There will not be any problem & - \\
There is no danger, it just a small operation & - \\
You will not have pain & Emphasizing the \\
There is no risk to life & negative \\
The injection will hurt a bit & - \\
There may be just a small bleeding & Focusing attention on \\
Tell me if you have any pain & the negatives \\
Are you experiencing any nausea or vertigo? & - \\
Is your heart sinking? & - \\
\hline
\end{tabular}

(26-32). Our study should prompt other similar studies to allow more meaningful comparison of results in future. Given the evidence base, the current knowledge and practices of our surgeons and anesthetists regarding NP are less than ideal, necessitating the need for creating awareness among them, as well as organizing objective training sessions for them in this crucial area of the doctor-patient communication. Educational interventions in the form of focused workshops for the residents as well as faculty members of surgery and anesthesia departments are recommended to address the deficiencies identified.

\section{Strengths and limitations}

Our study has some strengths as well as presents some limitations. It is the first institutional study which has attempted to assess the NP at our hospital and hence evolve an evidence base that could guide constructive changes in the communication pattern of our doctors towards this important but casually handled area of patient care. The limitations are as follows: Firstly the present study is a qualitative one rather than being a quantitative analysis of the patterns of communication with patients which are affected by numerous personal, family and social factors. Understandably an exact measure of the magnitude and pattern of harm/negative outcomes that resulted from the unintended nocebo words in clinical practice, was beyond the scope of the study. Secondly the present study did not include a control group for more robust comparison of the results. Thirdly as the present study is based on a single institution's data, its findings cannot be generalized to the rest of the hospitals in Pakistan. We suggest future well designed, multicenter studies to confirm our findings and improve upon our limitations. This will also allow meaning comparisons between different hospitals in future.

\section{Conclusion}

NP existed in the clinical practice of the surgeons and anesthetists during their communication with patients. It was more frequently observed in association with female gender of the involved professionals, residency status versus faculty position, and shorter professional experience $(<5$ years). There is need to create awareness among these professionals about the subtle negative messages conveyed by such communication and alert them that the nocebo effects have negative repercussions on the clinical outcomes of their patients. The professionals should be formally educated to avoid nocebo words and phrases.

\section{Acknowledgements}

We are grateful to the following doctors for helping us in collecting data from the participants: Dr Shahzad Ahmad, Dr Nosheen Faheem, Dr Faheem Ullah, Dr Muhammad Salman Zaib, Dr Ayaz-ud-Din and Dr Saad Siddiqui.

Ethical issues

Informed consent was taken from the participants for inclusion in the study. The study was conducted in accordance with the Declaration of Helsinki of 1975, as revised in 1983 and anonymity of the participants was ensured.

\section{Competing interests}

The authors declare that they have no competing interests.

Authors' contributions

KUZ and MS conceived and designed the study. MS and BA performed the literature search and wrote the manuscript. All authors participated in the data acquisition, analysis and interpretation. All authors critically reviewed, refined and approved the manuscript.

\section{Authors' affiliations}

1'Department of Obstetrics \& Gynecology, Mother and Child Health Centre, Pakistan Institute of Medical Sciences, Shaheed Zulfiqar Ali Bhutto Medical University, Islamabad, Pakistan. ${ }^{2}$ Department of Plastic Surgery and Burns, Pakistan Institute of Medical Sciences, Islamabad, Pakistan. ${ }^{3}$ Departments of Neurosurgery and Medical Education, Pakistan Institute of Medical Sciences, Shaheed Zulfiqar Ali Bhutto Medical University, Islamabad, Pakistan.

\section{References}

1. Colloca $L$, Sigaudo M, Benedetti F. The role of learning in nocebo and placebo effects. Pain 2008; 136: 211-8. doi: 10.1016/j. pain.2008.02.006

2. Koyama T, McHaffie JG, Laurienti PJ, Coghill RC. The subjective experience of pain: where expectations became reality. Proc Natl Acad Sci U S A 2005; 102: 12950-5. doi: 10.1073/ pnas.0408576102

3. Kennedy WP. The nocebo reaction. Med World 1961; 95: 203-5.

4. Colloca L, Miller FG. The nocebo effect and its relevance for clinical practice. Psychosom Med 2011; 73: 598-603. doi: 10.1097/psy.0b013e3182294a50

5. Enck P, Benedetti F, Schedlowski M. New insights into the placebo and nocebo responses. Neuron 2008; 59: 195-206. doi: 10.1016/j.neuron.2008.06.030

6. Klosterhalfen S, Kellermann S, Braun S, Kowalski A, Schrauth M, Zipfel S, et al. Gender and the nocebo response following conditioning and expectancy. J Psychosom Res 2009; 66: 3238. doi: 10.1016/j.jpsychores.2008.09.019

7. Benedetti F, Lanotte M, Lopiano L, Colloca L. When words are painful: unraveling the mechanisms of the nocebo effect. Neuroscience 2007; 147: 260-71. doi: 10.1016/j. neuroscience.2007.02.020

8. Colloca L, Benedetti F. Placebo analgesia induced by social observational learning. Pain 2009; 144: 28-34. doi: 10.1016/j. pain.2009.01.033

9. Scott DJ, Stohler CS, Egnatuk CM, Wang H, Koeppe RA, Zubieta JK. Placebo and nocebo effects are defined by opposite opioid and dopaminergic responses. Arch Gen Psychiatry 2008; 65: 220-31. doi: 10.1001/archgenpsychiatry.2007.34

10. Benedetti F, Amanzio M, Vighetti S, Asteggiano G. The biochemical and neuroendocrine bases of the hyperalgesic 
nocebo effect. J Neurosci 2006; 26: 12014-22. doi: 10.1523/ JNEUROSCI.2947-06.2006

11. Keltner JR, Furst A, Fan C, Redfern R, Inglis B, Fields HL. Isolating the modulatory effect of expectation on pain transmission: a functional magnetic resonance imaging study. J Neurosci 2006; 26: 4437-43. doi: 10.1523/jneurosci.4463-05.2006

12. Lorenz J, Hauck M, Paur RC, Nakamura Y, Zimmermann R, Bromm B, et al. Cortical correlates of false expectations during pain intensity judgments--a possible manifestation of placebo/ nocebo cognitions. Brain Behav Immun 2005; 19: 283-95. doi: 10.1016/j.bbi.2005.03.010

13. Bejenke CJ. Suggestive communication: its wide applicability in somatic medicine. In: Varga $\mathrm{K}$, editor. Beyond the words: communication and suggestion in medical practice. New York: Nova Science Publishers; 2011. p. 83-96.

14. Hansen E, Bejenke C. [Negative and positive suggestions in anaesthesia: Improved communication with anxious surgical patients]. Der Anaesthesist 2010; 59: 199-209. doi: 10.1007/ s00101-010-1679-9

15. Häuser W, Hansen E, Enck P. Nocebo phenomena in medicine: Their relevance in everyday clinical practice. Dtsch Arztebl Int 2012; 109: 459-65.

16. Hansen E, Zimmermann M, Dünzl G. [Hypnotic communication with emergency patients]. Notfall Rettungsmed 2010; 13: 31421. doi: $10.1007 / \mathrm{s} 10049-010-1293-z$

17. Hansen E. [Negative suggestions in medicine]. Z Hypnose Hypnother 2011; 6: 65-82.

18. Colloca $L$. The influence of the nocebo effect in clinical trials. Open Access J Clin Trials 2012; 4: 61-8. doi: 10.2147/oajct. s33730

19. Ciaramella A, Paroli M, Poli P. An emerging dimension in psychosomatic research: The nocebo phenomenon in the management of chronic pain. ISRN Neuroscience 2013: 574526. doi: $10.1155 / 2013 / 574526$

20. Saaiq M, Zaman KU. Breaking bad news in emergency: How do we approach it? Ann Pak Inst Med Sci 2006; 2: 72-4.

21. Saaiq M, Zaman KU. Casual consent to treatment: a neglected issue in our health care system. Ann Pak Inst Med Sci 2006; 2:
207-12.

22. Saaiq M, Zaman KU. Pattern of satisfaction among Neurosurgical inpatients. J Coll Physicians Surg Pak 2006; 16: 455-9.

23. Cheek D. Importance of recognizing that surgical patients behave as though hypnotized. Am J Clin Hypnosis 1962; 4: 227-31. doi: 10.1080/00029157.1962.10401905

24. Lang EV, Benotsch EG, Fick LJ. Adjunctive non-pharmacological analgesia for invasive medical procedures: a randomised trial. Lancet 2000; 355: 1486-90. Doi: 10.1016/S0140-6736(00)02162-0

25. Varelmann D, Pancaro C, Cappiello EC, Camann WR. Nocebo induced hyperalgesia during local anesthetic injection. Anesth Analg 2010; 110: 868-70. doi: 10.1213/ane.0b013e3181cc5727

26. Lombardi C, Gargioni S, Canonica GW, Passalacqua G. The nocebo effect during oral challenge in subjects with adverse drug reactions. Eur Ann Allergy Clin Immunol 2008; 40: 138-41.

27. Mondaini N, Gontero P, Giubilei G. Finasteride $5 \mathrm{mg}$ and sexual side effects: how many of these are related to a nocebo phenomenon? J Sex Med 2007; 4: 1708-12. doi: 10.1111/j.17436109.2007.00563.x

28. de la Cruz M, Hui D, Parsons HA, Bruera E. Placebo and nocebo effects in randomized double-blind clinical trials of agents for the therapy for fatigue in patients with advanced cancer. Cancer 2010; 116: 766-74. doi: 10.1002/cncr.24751

29. Silvestri A, Galetta P, Cerquetani E. Report of erectile dysfunction after therapy with beta-blockers is related to patient knowledge of side effects and is reversed by placebo. Eur Heart $J$ 2003; 24: 1928-32. doi: 10.1016/j.ehj.2003.08.016

30. Liccardi G, Senna G, Russo M. Evaluation of the nocebo effect during oral challenge in patients with adverse drug reactions. $J$ Investig Allergol Clin Immunol 2004; 14: 104-7.

31. Manchikanti L, Pampati V, Damron K. The role of placebo and nocebo effects of perioperative administration of sedatives and opioids in interventional pain management. Pain Physician 2005; 8: 349-55.

32. Faasse K, Petrie KJ. The nocebo effect: patient expectations and medication side effects. Postgrad Med J 2013; 89: 540-6. doi: $10.1136 /$ postgradmedj-2012-131730

\section{Key Messages}

\section{Implications for policy makers}

- Given the high frequency of subtle nocebo phenomenon involved in the doctor-patient communication, there is need to revisit the communication skills of doctors.

- As the flaws in communication skills remain subtle, the medical professionals need be made aware of the counterproductive words and phrases in their routine communication with patients.

- The situation calls for educational interventions such as focused workshops for doctors, to remedy the deficiencies identified.

- Future well designed and controlled studies are needed to confirm and improve the results of the current study.

\section{Implications for public}

Public education and awareness regarding nocebo phenomenon will serve as an impetus for improved communication skills of the doctors. 